\title{
ESPACIALIDADE DA ECONOMIA: INOVAÇÃO E ESTRATÉGIAS ESPACIAIS NO SETOR DE BASE FLORESTAL BRASILEIRO
}

\section{Spatiality of the economy: spatial strategies and innovation in the Brazilian forest-based sector}

\author{
Fernando dos Santos Sampaio ${ }^{1}$ \\ Marinez da Silva Mazzochin²
}

\begin{abstract}
RESUMO
A análise do processo de acumulação do capital de um determinado setor econômico deve levar em consideração as contradições inerentes ao seu processo de desenvolvimento. O setor industrial específico o qual teceremos algumas considerações é o setor de base florestal. Buscamos compreender essas contradições no processo de desenvolvimento da cadeia agroindustrial desse setor, apontando alguns fatores que propiciaram o desenvolvimento de uma moderna silvicultura, baseada nas pesquisas científicas, sobretudo em relação à matéria-prima, atendendo as necessidades industriais.
\end{abstract}

Palavras-chave: matéria-prima; espacialização; tecnologia; agricultura; indústria.

\begin{abstract}
The analysis of the accumulation process of the capital about a determined economical sector should take the inherent contradictions about your development process into account. The specific industrial sector that we will study about is the forest base. We intend to understand these contradictions about the development process in a chain of field industrial of this sector, pointing out some factors that started the development of a modern silviculture, based on the scientific researches, especially in relationship to raw material, attending to industrial necessities.
\end{abstract}

Keywords: raw material; spatialization; technology; agriculture; industry.

1 Doutor em Geografia Humana pela Universidade de São Paulo-USP. Professor do programa de Pós-Graduação em Geografia da Unioeste - Francisco Beltrão. Membro do Grupo de Pesquisa Dinâmica Econômica e Formação Socioespacial. Endereço Eletrônico: fernandosampaio_cch@yahoo.com.br.

2 Bacharel e Licenciada em Geografia pela Universidade Estadual do Oeste do Paraná - Unioeste - Francisco Beltrão. Aluna do Programa de Pós-Graduação em Geografia da Unioeste. Membro do Grupo de Pesquisa Dinâmica Econômica e Formação Socioespacial. Endereço Eletrônico: mmazzochin@yahoo.com.br. 


\section{INTRODUÇÃO}

A produção do espaço geográfico deve ser entendida no contexto da relação dialética entre o avanço das forças produtivas e das relações de produção. Nesse sentido, as pesquisas geográficas que estudam a dinâmica industrial são extremamente importantes para a Geografia, pois possibilitam o conhecimento das transformações do espaço a partir das novas relações de produção e o avanço das forças produtivas.

A partir das contradições encontradas nas indústrias e com a finalidade de aumentar a acumulação de capital, podemos compreender o funcionamento do modo de produção capitalista e as diferenças entre as classes sociais que constituem a sociedade.

O setor industrial específico o qual teceremos algumas considerações é o setor de base florestal. A gênese deste setor está atrelada ao processo de apropriação dos recursos florestais naturais, a priori via extrativismo vegetal, cujos processos de extração e industrialização eram bastante arcaicos. Alguns fatores como escassez da matéria-prima, protecionismo ambiental, características genéticas da madeira natural, entre outros, propiciaram o desenvolvimento de uma moderna silvicultura, que pauta-se nas pesquisas científicas e atende as necessidades industriais.

Nesse sentido, a disseminação de cursos de graduação e pós-graduação, bem como o desenvolvimento de pesquisas de institutos e órgãos públicos em parceria com empresas privadas do setor, proporcionou uma gama de inovações que, alavancadas pelo processo de modernização da agricultura, dinamizaram a conjuntura do setor.

O presente artigo busca compreender essas contradições no processo de desenvolvimento da cadeia agroindustrial do setor de base florestal fazendo algumas considerações sobre a dinâmica desse setor, enfocando a espacialização da origem da matéria-prima e a tecnologia voltada para esta área, sobretudo questões ligadas à pesquisa e desenvolvimento.

A metodologia utilizada consiste na análise de informações de autores que desenvolveram considerações sobre o tema, a leitura de documentos específicos como relatórios, anuários, entre outros, dos institutos e órgãos oficiais do setor de base florestal, a coleta de dados empíricos por meio de entrevistas e trabalhos de campo e a análise dos dados estatísticos existentes em diversos órgãos como IBGE (Instituto Brasileiro de Geografia e Estátistica), ABRAF (Associação Brasileira de Produtores de Florestas Plantadas), ABIMCI (Associação Brasileira da Indústria de Madeira Processada
Mecanicamente), ABRAFLOR (Associação Brasileira de Produtores de Florestas Plantadas), MAPA (Ministério da Agricultura, Pecuária e Abastecimento), entre outros.

\section{CARACTERIZAÇÃO DO SETOR DE BASE FLORESTAL}

A cadeia produtiva com base no setor florestal, conforme apresentada na figura 1, constitui uma atividade econômica complexa e diversificada de produtos e aplicações energéticas e industriais. No mundo inteiro, o setor florestal tem importância como fornecedor de energia ou matéria-prima para a indústria da construção civil e de transformação.

No Brasil, este setor apresenta características mais singulares em razão do país estar entre os principais detentores de recursos florestais abundantes, sendo o único que possui extensa área de florestas tropicais.

Entretanto, o Brasil desenvolveu uma complexa estrutura produtiva no setor florestal, em decorrência de suas florestas nativas, da importância mundial da indústria de papel e celulose e de suas florestas de pinus e eucaliptos e das relações entre os produtores de equipamentos, insumos, projetos de engenharia e as empresas de produtos florestais.

Conforme Brasil (2007), o país convive com dois modelos de organização industrial presentes em se tratando do setor de base florestal. De um lado, os setores de celulose, papel, lâmina de madeira, chapa de fibra e madeira aglomerada são dominados por poucas empresas de grande porte, integradas verticalmente da floresta até produtos acabados, que monopolizam completamente a produção e o comércio.

De outro, na produção de madeira serrada, compensados e móveis, existe um grande número de empresas de pequeno e médio porte, de menor capacidade empresarial. No caso da indústria de móveis, além da variedade no uso de materiais, o setor apresenta uma forte pulverização das preferências dos consumidores, levando a uma redução da escala da demanda e a uma enorme fragmentação do mercado.

De acordo com a ABIMCI (2007), o Brasil possui cerca de 550 milhões de hectares de floresta nativa, representando cerca de $10 \%$ de toda a área florestal do mundo. Destes, $60 \%$ são florestas tropicais, $34 \%$ cerrados, $4 \%$ matas de caatinga e $2 \%$ de mata atlântica. A distribuição das florestas nativas encontra-se demonstrada na tabela 1. 


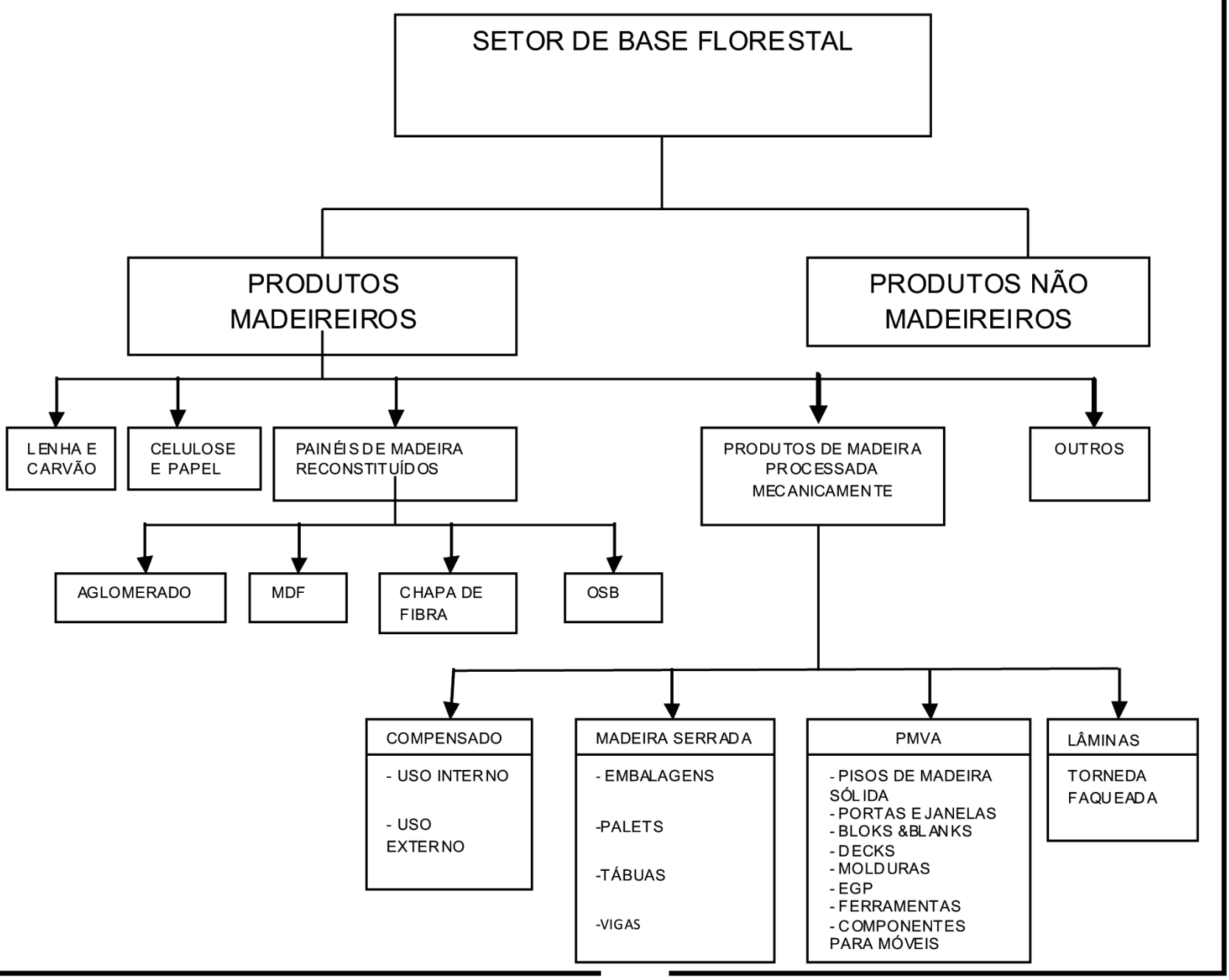

FIGURA 1 - ESTRUTURA DA CADEIA PRODUTIVA DO SETOR DE BASE FLORESTAL

Fonte: ABIMCI (2007).

TABELA 1 - DISTRIBUIÇÃO DAS FLORESTAS NATIVAS DE PRODUÇÃO NOS PRINCIPAIS ESTADOS BRASILEIROS (2005)

\begin{tabular}{|c|c|c|}
\hline Estado & Área (milhões ha) & Participação (\%) \\
\hline Amazonas & 68,9 & 32,6 \\
\hline Pará & 61,9 & 29,3 \\
\hline Mato Grosso & 25,6 & 12,1 \\
\hline Rondônia & 9,9 & 4,7 \\
\hline Outros $^{*}$ & 45,2 & 21,3 \\
\hline Total $^{211,5}$ & $\mathbf{1 0 0 , 0}$ \\
\hline
\end{tabular}

Fonte: $\mathrm{ABIMCl}(2008)$.

*Outros: Acre, Maranhão, Amapá, Roraima e Tocantins. 
As florestas nativas brasileiras podem ser divididas, ainda, em três biomas principais: as florestas tropicais, na Amazônia e em remanescentes da Mata Atlântica; as florestas de cerrado, no Planalto Central; e as florestas semi-temperadas, na Região Sul.

Conforme Brasil (2007) a retirada da cobertura vegetal original, formada na maior parte por florestas tropicais, é um traço distintivo do processo de ocupação e desenvolvimento da economia brasileira.

Até os anos 1950, o território nacional era quase totalmente coberto por florestas nativas. O desenvolvimento urbano e industrial intensificou a utilização dos recursos florestais naturais e o desmatamento avançou rapidamente, em especial, nas Regiões Sul, Sudeste e Nordeste do Brasil (BRASIL, 2007).
Após quase completa escassez da vegetação nativa, em 1964 o governo brasileiro criou a Lei $n^{\circ} 5.106$, de 02 de setembro de 1966, onde dispôs sobre os incentivos concedidos a empreendimentos florestais. A partir disso, e, somada ao crescente protecionismo ambiental e a outros fatores determinantes, a origem da matéria-prima para atividades do setor de base florestal passou, em grande parte, a originar-se de florestas plantadas.

De acordo com a ABRAF (2008), as florestas plantadas no Brasil atingiram, em 2007, aproximadamente 5.560.230 ha, representando um aumento de 186.786 ha em relação a 2006. No período de 2005 a 2007, constatou-se um incremento na área plantada de 318.428 ha, com decréscimo de $1,4 \%$ em pinus e acréscimo de $10,1 \%$ no eucalipto, conforme informações apresentadas no gráfico 1.

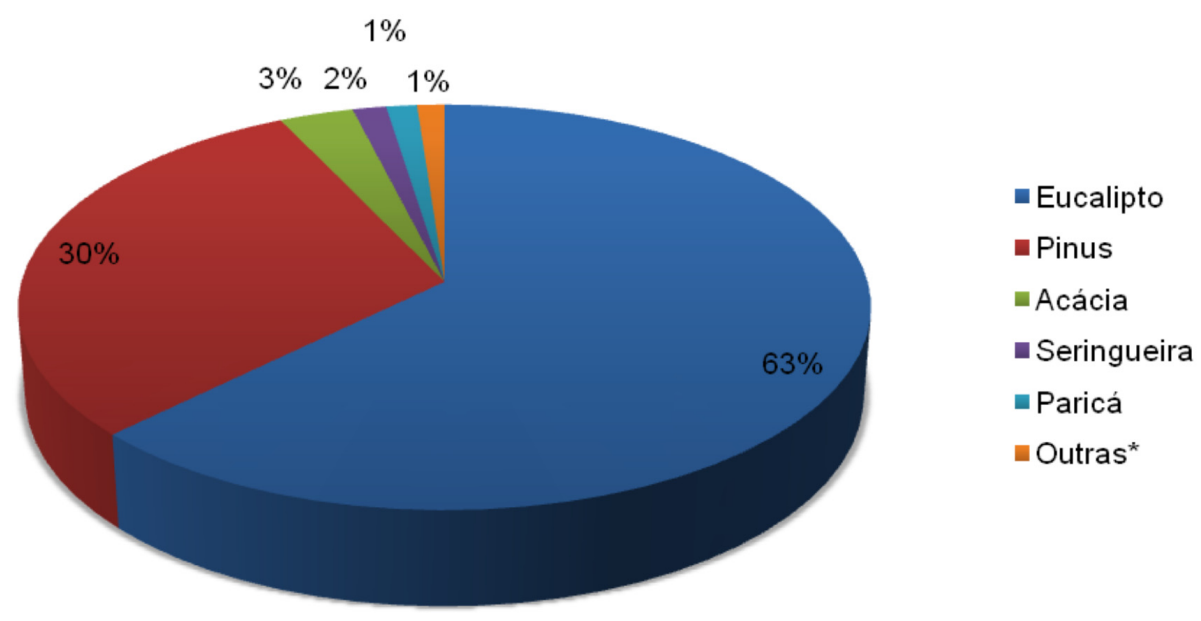

GRÁFICO 1 - DISTRIBUIÇÃO DAS ÁREAS DE FLORESTAS PLANTADAS POR ESPÉCIES (2007)

FONTE: Organizado pelos autores com base nos dados da $\mathrm{ABIMCI}(2008)$.

De acordo com Brasil (2007), os reflorestamentos, até 1985, concentravam-se nos Estados de Minas Gerais, São Paulo, Paraná, Santa Catarina, Rio Grande do Sul e Mato Grosso do Sul, que detinham cerca de $90 \%$ da área total plantada. Recentemente, com o processo de desconcentração industrial, novas regiões aumentaram sua participação nesse processo, tais como Bahia, Pará e Amapá.

No entanto, a maior concentração de áreas com florestas plantadas de pinus encontra-se na região sul do país, a qual possui 1.432 mil ha, além de 419 mil ha de área plantada com florestas de eucalipto. Em contrapartida, a região Sudeste concentra $57 \%$ das florestas plantadas com eucaliptos do Brasil, o que representa $2.138 \mathrm{mi} / \mathrm{ha}$. As regiões Norte, Centro-Oeste e Nordeste possuem grande concentração de eucalipto, totalizando em 1.194 mil ha. (ABIMCI, 2008), conforme dados apresentados nos mapas 1 e 2 . 


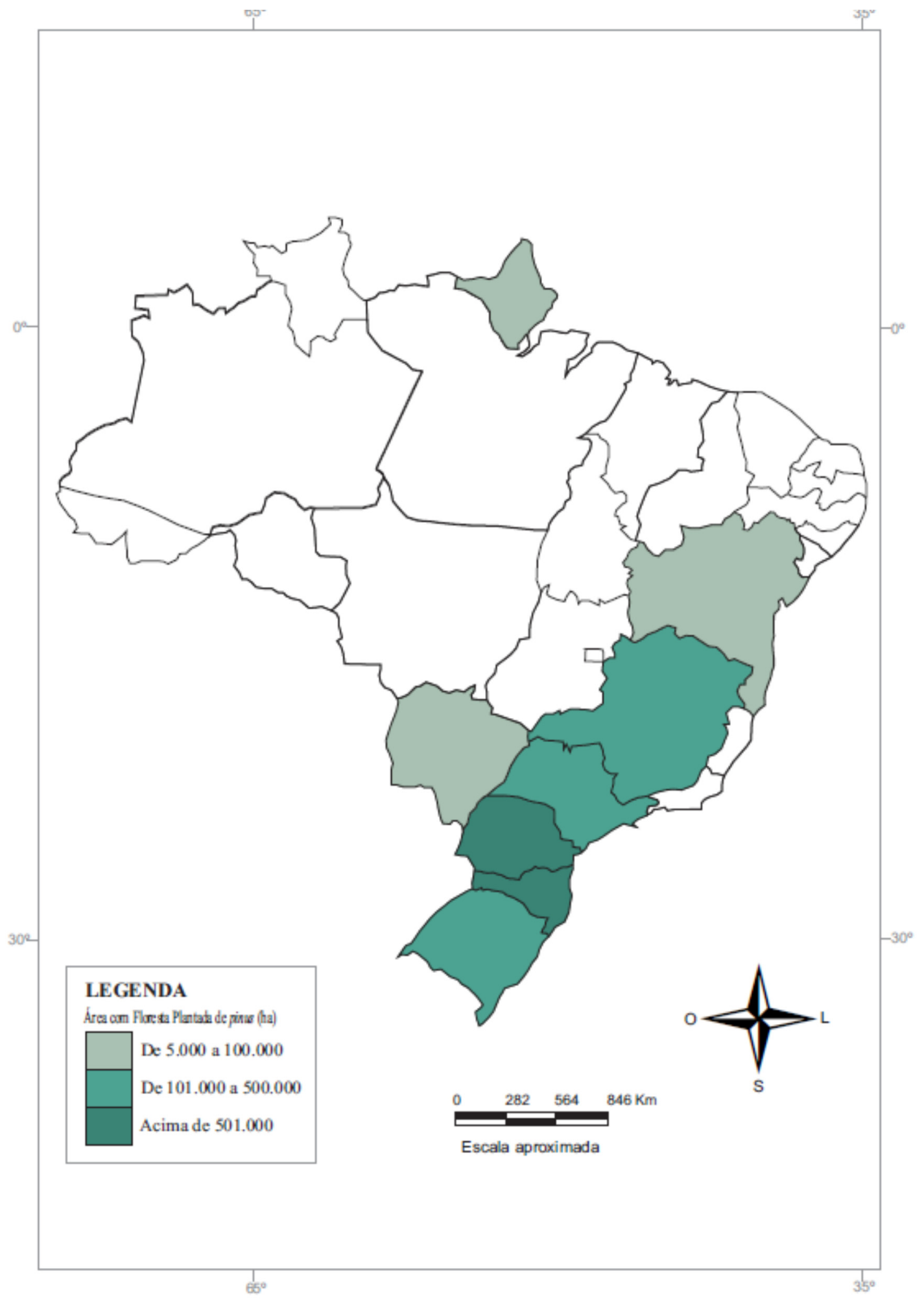

MAPA 1 - PRINCIPAIS ÁREAS DE FLORESTA PLANTADA COM PINUS NO BRASIL (2007)

FONTE: ABRAF (2008). Org.: Marinez S. Mazzochin. Desenho: Edson Luiz Flores / Fernando Sampaio 


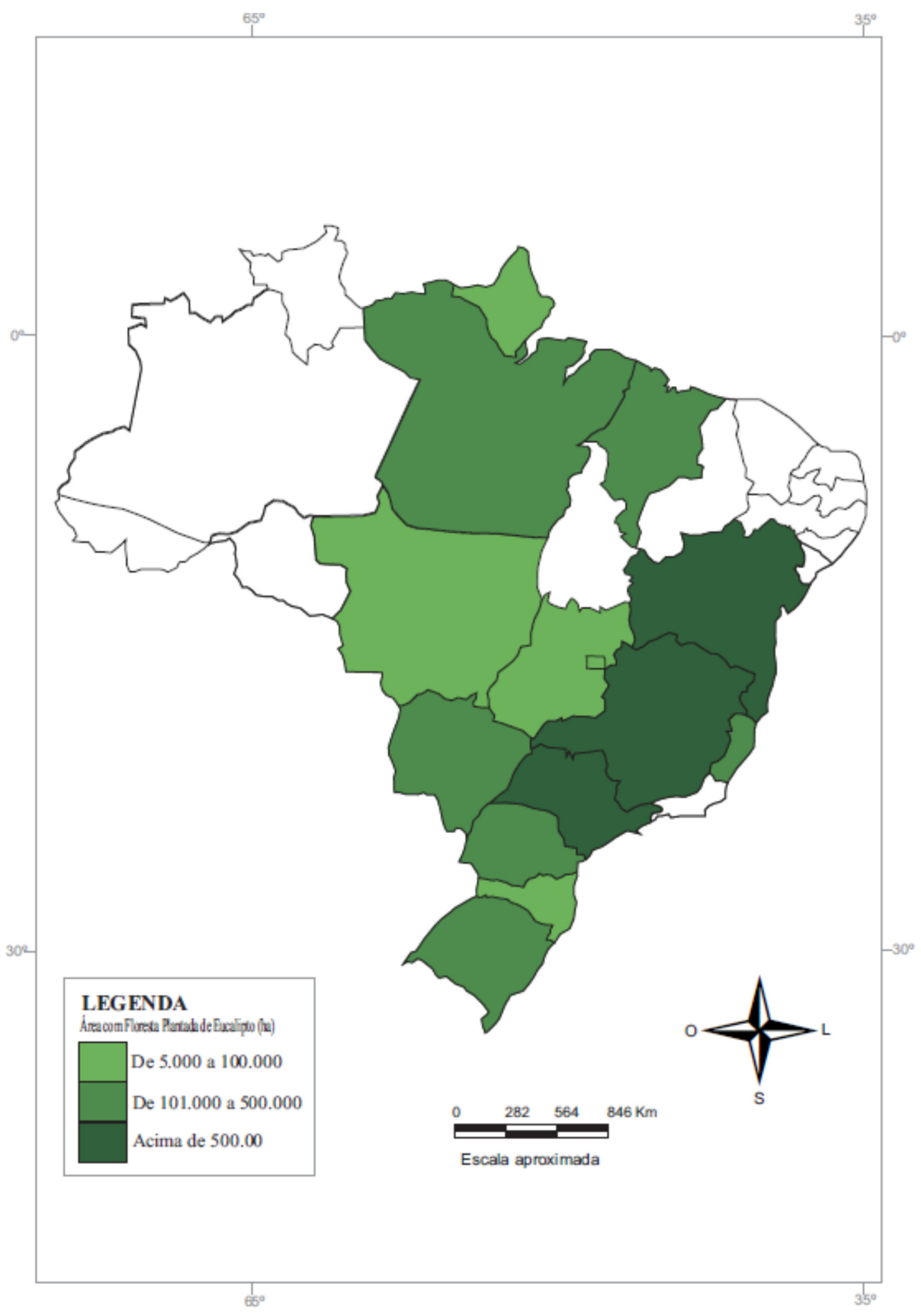

MAPA 2 - PRINCIPAIS ÁREAS DE FLORESTA PLANTADA COM EUCALIPTO NO BRASIL (2007)

FONTE: ABRAF (2008). Org.: Marinez S. Mazzochin. Desenho: Edson Luiz Flores / Fernando Sampaio 
Conforme Martini (2003), a madeira de pinus é a principal fonte de matéria-prima para a indústria de transformação primária, localizada na Região Sul, e a nova alternativa de suprimento de matéria-prima é a madeira de eucalipto.

De acordo com a ABRAF (2008), 95,3\% da produção sustentável de madeira em tora de pinus concentra-se nas regiões Sul e Sudeste. Esta concentração deve-se ao nível de desenvolvimento da indústria madeireira nestas regiões, envolvendo principalmente a fabricação de madeira serrada, compensado e painéis reconstituídos.

Em relação à produção de madeira em tora de eucalipto, aproximadamente $86 \%$ da produção sustentável nacional da espécie se concentra nas regiões Sudeste, Nordeste e Sul. Estas florestas plantadas estão associadas às indústrias de papel e celulose, siderúrgicas a carvão vegetal e de painéis de madeira reconstituída instaladas nestas regiões.

\subsection{PAPEL DO ESTADO NA REGULAMENTAÇÃO DO SETOR}

O setor florestal produtivo, como é conhecido atualmente, teve sua origem no Brasil Império com a extração da madeira nativa, principalmente o pau-brasil. Nesta fase inicial, as matas eram vistas apenas como fonte de receita e eram gerenciadas pela Fazenda, com o objetivo exclusivo de colher os lucros obtidos com a atividade madeireira.

Em 1860, foi criada a Secretaria de Agricultura, Comércio e Obras Públicas, que viria a gerenciar questões relacionadas à agricultura, comércio, obras públicas, minas, terra, colonização, imigração, catequese dos índios, correios e telégrafos. No entanto, a preocupação deste órgão em relação ao setor florestal pautava-se apenas na questão econômica.

A preocupação com a proteção das florestas emerge no século $X X$, quando encontrava-se esgotada uma parte considerável das florestas nativas, vistas como um entrave à expansão das fronteiras agrícolas. Mesmo depois de já esgotadas as reservas de paubrasil, a atividade extrativista desenfreada prevaleceu no Brasil sobre outras espécies nativas, sobretudo a exploração do pinho nacional (Araucária angustifólia).

Em 1921 foi criado o Serviço Florestal do Brasil, e mais tarde surgiram outras instituições como: Departamento de Recursos Naturais Renováveis, Instituto Nacional do Pinho, Instituto Nacional do Mate, Instituto Brasileiro do Desenvolvimento Florestal (IBDF) ${ }^{3} \mathrm{e}$, por último, o Instituto Brasileiro do Meio Ambiente e dos Recursos Naturais Renováveis (IBAMA), criado pela Lei $n^{\circ} 7735$, de 22 de fevereiro de 1989, atual responsável pela política florestal brasileira (BRASIL, 2007).

No ano de 2007 ocorreu a divisão do IBAMA, com a criação do Instituto Chico Mendes de Conservação da Biodiversidade (ICMBio), através da Lei $n^{\circ} 11.516$, de 28 de agosto de 2007. A principal atribuição do ICMBio é administrar as Unidades de Conservação (UCs) federais, até então de atribuição do IBAMA ${ }^{4}$.

\section{DINÂMICA CIENTIIFICA E TECNOLÓGICA DO SETOR DE BASE FLORESTAL}

O desenvolvimento do setor florestal, bem como o surgimento de instituições ligadas a este ramo ocasionou a necessidade de capacitação profissional e formação de cientistas na área florestal.

Conforme Brasil (2002), a crise do petróleo da década de 1970 incentivou as pesquisas sobre a energia da biomassa florestal e a produção de carvão vegetal, que reduziram gradativamente na década de 1980 , onde ocorreu um aumento das pesquisas na área de celulose e papel. As serrarias e fabricantes de compensados são, em sua maioria, pequenas empresas, operando com escasso capital de giro e equipamentos antigos e de baixa produtividade.

Entretanto, as fábricas de chapas duras, $\mathrm{MDF}^{5} \mathrm{e}$ $\mathrm{OSB}^{6}$, e aglomerados são modernas ou em fase de modernização, bem capitalizadas e com amplo acesso à tecnologia de processo e de produto.

3 Responsável pela promulgação do Código Florestal Brasileiro em 1965, estando em vigência até os dias atuais.

4 Ao IBAMA, restaram as atribuições de polícia ambiental, autorização do uso de recursos naturais e os polêmicos licenciamentos de empreendimentos com impactos no ambiente. Já o Instituto Chico Mendes, além das 292 unidades federais de conservação em todo o Brasil, lidará com programas de pesquisa da biodiversidade. (SOCIEDADE BRASILEIRA PARA O PROGRESSO DA CIÊNCIA, 2007)

5 O MDF (Mediu Density Fiberboard) é uma chapa fabricada a partir da trituração da madeira por um equipamento chamado desfibrador. Neste, a madeira é cortada em pequenos cavacos e é misturada com resinas sintéticas, onde a ação da temperatura e pressão produzem uma chapa lisa e homogênea, com consistência e algumas características que se assemelham à madeira maciça. (MACEDO; ROQUE, 2008).

6 OSB (Oriented Strand Board) é um painel de madeira com uma liga de resina sintética, feita de três camadas prensadas com tiras de madeira ou "strands", alinhados em escamas, de acordo com a EN 300 OSB (Norma Europeia). Ela é feita predominantemente de madeira reflorestada. Os painéis altamente selecionados podem ser usados para determinados tipos de bordas e variadas aplicações. (MACEDO; ROQUE, 2008). 
Além da ênfase ao fortalecimento da indústria de celulose e papel, ao uso do carvão vegetal na siderurgia e ao processamento mecânico da madeira, o Brasil vem se desenvolvendo em outros setores, como é o caso da indústria do processamento mecânico do látex da seringueira e dos óleos essenciais de eucalipto.

Destaca-se também a produção de goma resina de pinus, que colocou o país em posição de destaque no cenário mundial e que ainda apresenta um grande potencial de crescimento (BRASIL, 2002). Outro tema que merece destaque dentro do setor florestal é o consumo de madeira como fonte energética, fonte primária de energia em nosso país.

Em termos da capacidade instalada de ensino e pesquisa voltada para o setor de base florestal, o Brasil conta com 24 escolas de graduação em Engenharia Florestal, que já formaram 7.716 profissionais e oferecem anualmente 1.199 novas vagas. Nove dessas escolas apresentam programas de pós-graduação, que já formaram 1.654 Mestres e 286 Doutores.

Em termos de geração de pesquisa florestal, o diretório de Grupos de Pesquisas do CNPq revela a existência de 547 grupos de pesquisa em todo o Brasil. Um levantamento da produção científica divulgada por
14 revistas nacionais especializadas revela um total de 2.239 trabalhos científicos, dos quais 1.313 foram divulgados no período de 1990 a 2002. (BRASIL, 2002).

O mapa 3 apresenta uma relação de Instituições de Ensino Superior em cursos de Engenharia Florestal no Brasil. As Instituições mais antigas (UFV, UFPR, UFRRJ, UFSA, USP e FCAP) formaram juntas $73 \%$ do número de profissionais até 2002.

A principal fonte geradora de pesquisa e desenvolvimento em ciência e tecnologia está nas Universidades com cursos de pós-graduação stricto sensu estruturados, ambos apresentados também no mapa 3.

Destaca-se, nesse aspecto, o papel importante do INPA (Instituto Nacional de Pesquisas da Amazônia), que mesmo não oferecendo curso de graduação voltado para a área florestal, possui um dos cursos mais antigos de pós-graduação stricto sensu na área.

Apesar da maior parte da produção científica florestal no Brasil ser gerada por pesquisadores ligados às Universidades, EMBRAPA, ou por institutos de pesquisas especializados, é notável a produção em algumas empresas de base florestal, principalmente as ligadas ao setor de papel e celulose, conforme apresentados no Quadro 1.

\begin{tabular}{|c|c|}
\hline Sigla & Instituição \\
\hline ARACRUZ & Aracruz Celulose S. A. \\
\hline BAHIASUL & Bahia Sul Celulose S. A. \\
\hline CENIBRA & Celulose Nipo Brasileira S. A. \\
\hline CVRD & Cia. Vale do Rio Doce \\
\hline DURATEX & Duratex S. A. \\
\hline EUCATEX & Eucatex S. A. Ind. E Com. \\
\hline GEOSAT & Geosat Geoprocessamento S/C Ltda. \\
\hline IP & Intenational Papel do Brasil Ltda. \\
\hline KLABIN & Klabin Fabricadora de Papel S. A. \\
\hline PETROBRAS & Petrobrás - Petróleo Brasileiro S. A. \\
\hline PISA & Pisa Florestal S. A. \\
\hline RIGESA & Rigesa Celulose Papel e Embalagens Ltda. \\
\hline RIPASA & Ripasa S. A.Celulose e Papel \\
\hline SUZANO & Cia. Suzano de Papel e Celulose \\
\hline VCP & Votorantim Celulose e Papel S. A. \\
\hline VERACEL & Veracel Celulose S. A. \\
\hline
\end{tabular}

QUADRO 1 - ENTIDADES PRIVADAS COM PESQUISAS NA ÁREA FLORESTAL

FONTE: BRASIL (2002, p. 19). 


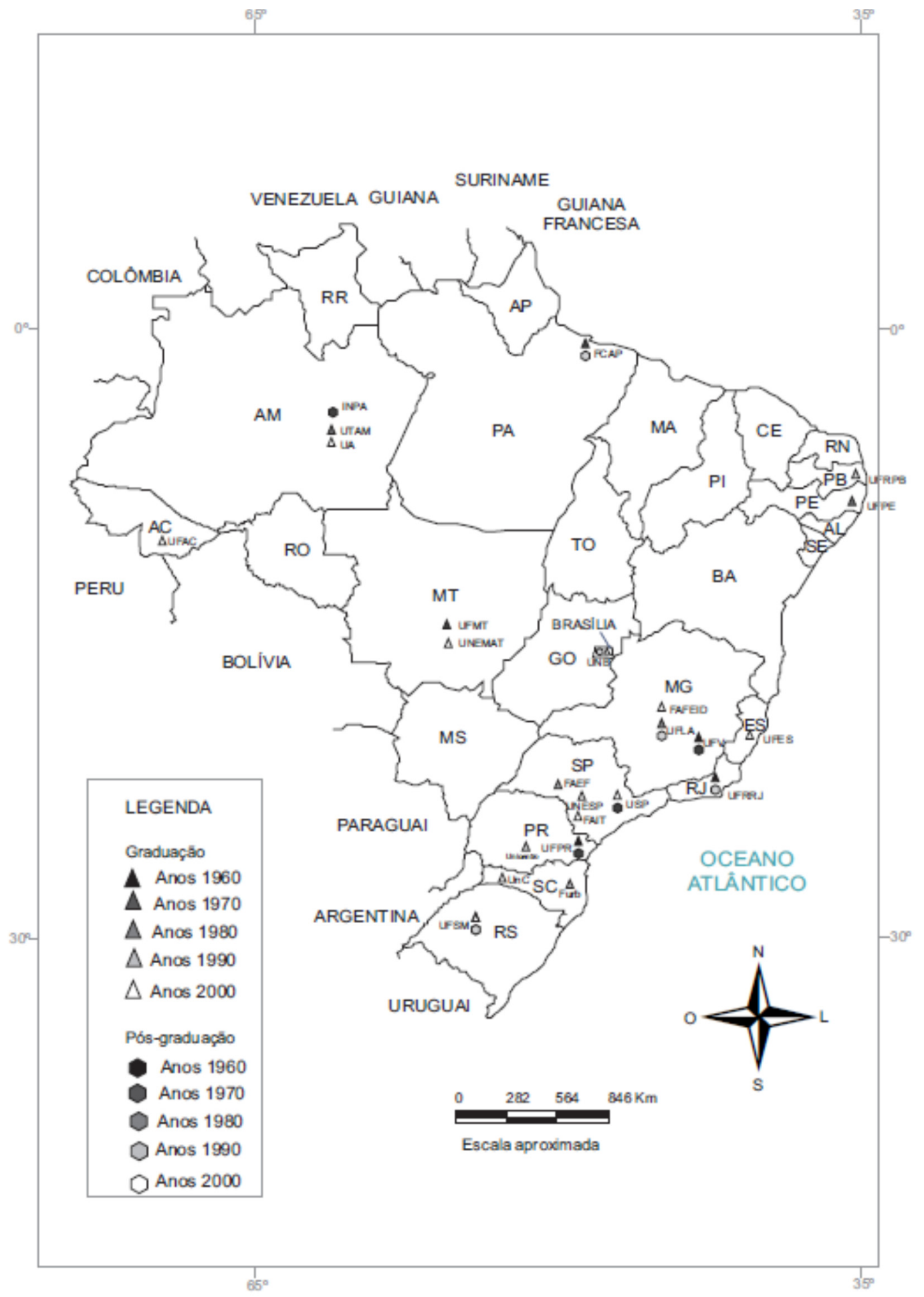

MAPA 3 - CURSOS DE ENGENHARIA FLORESTAL POR PERÍODO DE INSTALAÇÃO

FONTE: BRASIL (2002). Org.: Marinez S. Mazzochin. Desenho: Edson Luiz Flores / Fernando Sampaio 
Observa-se que a maioria das entidades privadas com pesquisa na área florestal são grandes produtoras de papel e celulose. O processo produtivo de celulose e papel, conforme Martini (2003), demanda alta tecnologia, não somente na inovação em processo e produto, mas principalmente na produção da matéria-prima na área florestal, pois é nesta etapa que serão definidas as espécies a serem plantadas com o objetivo de obter produto de acordo com os critérios de rendimento de celulose, crescimento vegetal e rendimento por área plantada.

Nesse sentido, a maioria das pesquisas desse setor estão voltadas exclusivamente para a solução de problemas intrínsecos a cada empresa em particular, não caracterizando uma investigação científica e tecnológica.

\subsection{INOVAÇÃO TECNOLÓGICA DA MATÉRIA- PRIMA}

A matéria-prima para o setor de base florestal, em sua grande maioria oriunda de florestas plantadas, passou por uma grande evolução no processo de plantio. O fomento dado pelo setor público e privado à pesquisa, bem como o programa de incentivos fiscais ao reflorestamento, ocasionou o desenvolvimento de uma silvicultura intensiva em plantações florestais de rápido crescimento, utilizando-se da genética molecular e genômica que passaram a predominar nas pesquisas da genética florestal, a partir de 1941.

Conforme apresentado anteriormente, o Brasil possui um suporte quantitativo e qualitativo para 0 desenvolvimento de pesquisa e desenvolvimento voltados para o setor de base florestal. Essas pesquisas, oriundas tanto de órgãos públicos quanto privados, fornecem todo um aparato de melhoramento genético que vai desde o tratamento com as mudas a serem cultivadas quanto com o produto a ser transportado para a indústria.

Conforme Brun (2008) a inovação no plantio consiste, atualmente, na utilização dos clones de eucalipto e experimentos com pinus taeda em colônias do sul do
Brasil. Mais de 1500 clones encontram-se em testes que visam o melhoramento genético das mudas de eucalipto e pinus, atuando na redução de substâncias que interferem na qualidade da madeira.

As indústrias se utilizam de toda uma gama de pesquisas voltadas para o desenvolvimento da excelência da madeira. Citamos como exemplo, o Programa Nacional de Qualidade da Madeira (PNQM), que tem o propósito de promover a melhoria da qualidade da madeira, disponibilizando produtos com especificações e parâmetros controlados.

\section{DESENVOLVIMENTO DO SETOR DE BASE FLORESTAL E A RELAÇÃO COM O PROCESSO DE MODERNIZAÇÃO DA AGRICULTURA}

A partir da década de 1930, o Brasil vai transformando-se de um país agrário-exportador para urbanoindustrial. Com a crise dos anos 1930, a fase B do $3^{\circ}$ ciclo de Kondratieff , o país adota uma política de substituição de importações, que vai ser a base central de seu processo de industrialização.

Com o governo de Getúlio Vargas, a burguesia industrial nascente torna-se sócia dos latifundiários, firmando assim o pacto de poder da $3^{\text {a }}$ dualidade, como apresentado por Rangel (1981) criando, assim, melhores condições para o processo de industrialização. No entanto, devido à característica deste pacto de poder, a industrialização ocorre sem alteração da estrutura agrária do país.

$\mathrm{Na}$ década de 1960, um intenso debate surge buscando compreender as consequências de não se ter mudado esta estrutura agrária. Os anos 1960 e 1970 serão o palco do que ficou conhecido como o processo de Modernização da Agricultura, base sob a qual teceremos algumas considerações ${ }^{8}$.

Nosso intuito é resgatar alguns aspectos importantes no processo de modernização da agricultura e o crescente avanço industrial. Estes aspectos, aliados ao dinamismo tecnológico existente e às condições sócioespaciais específicas, dinamizaram o setor de base florestal, sobretudo em relação à matéria-prima.

7 Nicolai Kondratieff (1892-1938), economista marxista russo, estudou com profundidade os ciclos econômicos, e evidenciou que a economia mundial passa por períodos de, aproximadamente, sessenta anos de ascensão (fase A) ou depressão (fase B), também chamados de ciclos de longa duração. Para Kondratieff, os Ciclos Longos no sistema capitalista resultam de sólidos investimentos ou de sua depreciação em infraestrutura, como: ferrovias, portos, canais, indústrias, saneamento básico, eletrificação, construção civil, etc. Nestes ciclos a fase de expansão é caracterizada por superinvestimentos em bens de capital e, na fase de depressão, por um processo de depreciação. (SANDRONI, 1999).

8 Não buscamos aqui levantar os pontos do debate clássico dos anos 1960, por mais que o consideremos importantes, pois há ampla bibliografia que expõe de forma mais focada suas características, como por exemplo, Gonçalves (1997), Linhares e Silva (1981), Marighella (1980), Prado Jr (1987), Rangel (1981) e Vieira (1992). 
Para Delgado (2001) o período de 1965-1980 constituiu a idade de ouro de desenvolvimento de uma agricultura capitalista em integração com a economia industrial e urbana e com o setor externo, sob forte mediação financeira do setor público.

Denominei este processo de integração técnica-agricultura-indústria, caracterizado de um lado pela mudança na base técnica de meios de produção utilizados pela agricultura, materializada na presença crescente de insumos industriais (fertilizantes, defensivos, corretivos do solo, sementes melhoradas e combustíveis líquidos, etc.); e máquinas industriais (tratores, colhedeiras, implementos, equipamentos de injeção, entre outros). De um lado ocorreu uma integração de grau variável entre a produção primária de alimentos e matérias-primas e vários ramos industriais (oleoginosos, moinhos, indústrias de cana e álcool, papel e papelão, fumo, têxtil, bebidas, etc.). (DELGADO, 2001, p.164).

É neste período que o Estado aprovou as principais normas e regimentos concedendo incentivos fiscais para empreendimentos baseados no setor de base florestal, o que aumentou consideravelmente o número destes.

Conforme Brasil (2007), no caso da política de reflorestamento, esse mecanismo foi crescentemente subordinado aos interesses da grande indústria consumidora de madeira.

O processo foi marcado tanto pela exigência de áreas de reflorestamento cada vez maiores, de experiência acumulada no setor florestal e de destinação da matéria-prima, quanto pelo aumento do poder de monopólio dessas empresas em relação aos produtores independentes.

No período de 1967 a 1986, foram reflorestados no Brasil cerca de seis milhões de hectares com base em projetos incentivados. Como indicado, esse proces- so permitiu a formação de uma base florestal capaz de garantir o fornecimento de matéria-prima de qualidade e a custo reduzido, viabilizando a expansão da indústria brasileira, entre outros, de celulose e papel e de produtos siderúrgicos com base em carvão vegetal.

Kautski apud Guimarães (1982) afirmava que na agricultura primitiva, esta era, do ponto de vista econômico, o elemento decisivo. A partir do processo de modernização da agricultura, a grande indústria capitalista passou a dominar. A agricultura passou a corresponder suas ordens e a adaptar-se às suas exigências. A direção da evolução industrial serve de regra à evolução agrícola.

Nesse sentido, uma parte dos produtos agrícolas não é mais consumida de forma natural, sendo adquirida e processada pela indústria. Uma parte das necessidades de consumo da agricultura não é mais obtida pelas explorações agrícolas, mas sim suprida pela indústria.

E assim ocorreu com a indústria do setor de base florestal, onde a indústria passou a determinar a espacialização da matéria-prima e passou a ser o carro-chefe dos processos de inovação em processos e produtos, atendendo a demanda do mercado interno e externo.

A Tabela 2 nos apresenta o consumo de madeira em toras de floresta plantadas para uso industrial no Brasil por segmento e espécie. Os dados nos mostram que a demanda de pinus está voltada, em maior parte, para a indústria madeireira, enquanto que a demanda de eucalipto esta voltada, em sua maior parte, para as indústrias de papel e celulose e carvão.

Mostramos que a região Sul do Brasil concentra as áreas de florestas plantadas de pinus (matéria-prima para a indústria madeireira). Nesta região encontram-se as maiores indústrias ligadas ao processo de transformação da madeira.

TABELA 2 - CONSUMO DE MADEIRA EM TORAS DE FLORESTA PLANTADAS PARA USO INDUSTRIAL NO BRASIL POR SEGMENTO E ESPÉCIE

\begin{tabular}{|l|c|c|c|}
\hline \multirow{2}{*}{ Segmento } & \multicolumn{3}{|c|}{ Consumo de Madeiras em Toras $\left(\mathbf{1 . 0 0 0} \mathbf{~ m}^{\mathbf{3}}\right) \mathbf{- 2 0 0 7}$} \\
\cline { 2 - 4 } & Pinus & Eucalipto & Total \\
\hline 1. Celulose e Papel & 7.231 & 40.271 & 47.502 \\
\hline 2. Painéis Reconstituídos & 6.194 & 1.737 & 7.931 \\
\hline 3. Indústria Madeireira & \multicolumn{3}{|}{} \\
\hline 3.1 Compensado & 5.445 & 124 & 5.599 \\
\hline 3.2 Serrados & 25.928 & 3.052 & 28.980 \\
\hline 4. Carvão & 0 & 37.352 & 37.352 \\
\hline 5. Outros & \multicolumn{3}{|c|}{} \\
\hline
\end{tabular}

*Incluindo o beneficiamento de Produtos de Maior Valor Agregado - PMVA (piso, porta, janela, molduta, ferramentas e EDGE GLUED PANEL - EGP).

**Incluindo cavaco de madeira para exportação e lenha de floresta plantada.

FONTE: ABRAF (2008) 
SAMPAIO, F. S.; MAZZOCHIN, M. S. Espacialidade da economia: inovação e estratégias...

A região Sudeste agrupa a maior área de florestas plantadas com eucaliptus (matéria-prima para as indústrias de papel e celulose e carvão). Nesta região concentram-se as maiores indústrias de papel e celulose e também as maiores siderúrgicas que utilizam o carvão como fonte de energia. Sendo assim, podemos observar a espacialização das florestas plantadas, e sua localização que busca atender uma lógica da dinâmica industrial.

Por fim, devemos considerar o papel importante das inovações tecnológicas nesse processo todo. $O$ setor de base florestal, após quase completa escassez da matéria-prima e aliado aos fatores conjunturais do país depois da década de 1960, perpassou por todo um processo de inovação tecnológica em processo e produto.

\section{CONSIDERAÇÕES FINAIS}

A produção do espaço geográfico deve ser entendida no contexto da relação dialética entre o avanço das forças produtivas e das relações de produção. Os avanços técnicos nos setores produtivos marcam intensamente a dinâmica espacial da acumulação de capitais, assim entendemos que o estudo dos avanços técnicos no processamento da madeira é uma base fundamental para o entendimento deste setor.

O setor de base florestal possui um dinamismo intenso. A cadeia produtiva compreende a silvicultura, a extração florestal e toda uma gama de direcionamentos e produtos que podem se interpenetrar no decorrer do processo.

Nesse sentido, a acumulação de capital, presente na indústria do setor de base florestal, trouxe uma nova configuração espacial desse setor. A escassez de matéria-prima aliada ao protecionismo ambiental impulsionou a substituição das florestas nativas pelas florestas plantadas.

Nesse contexto, a indústria passou a determinar a espacialização da matéria-prima e passou a ser o carrochefe da inovação em processos e produtos, atendendo para a demanda do mercado interno e externo.

As inovações no plantio estão associadas a um processo maior de modernização da agricultura. Percebemos a importância do componente tecnológico. Deixamos claro, no entanto, que esse recorte não nos permite conhecer com profundidade todas as determinações do setor.

\section{REFERÊNCIAS}

ASSOCIAÇÃO BRASILEIRA DA INDÚSTRIA DE MADEIRA PROCESSADA MECANICAMENTE (ABIMCI). Estudo Setorial 2007. Curitiba: ABIMCI, 2007.

ASSOCIAÇÃO BRASILEIRA DA INDÚSTRIA DE MADEIRA PROCESSADA MECANICAMENTE (ABIMCI). Estudo Setorial 2008. Curitiba: ABIMCI, 2008.

ASSOCIAÇÃO BRASILEIRA DE CELULOSE E PAPEL (BRACELPA). Relatório Estatístico 2007/2008. Disponível em: <http://www.bracelpa.org.br/bra/estatisticas/pdf/anual/rel2007. pdf>. Acesso em: 20/04/2009.

ASSOCIAÇÃO BRASILEIRA DE PRODUTORES DE FLORESTAS PLANTADAS (ABRAF). Anuário Estatístico da ABRAF 2008. Brasília: ABRAF, 2008.

BRASIL. Ministério da Agricultura, Pecuária e Abastecimento. Cadeia produtiva de madeira. Brasília, 2007. Disponível em: <http://www.iica.org.br/Docs/CadeiasProdutivas/Cadeia\%20 Produtiva $\% 20$ de $\% 20$ Florestas $\% 2$ Plantadas $\% 20$ e $\% 20$ Madeira.pdf>. Acesso em: 04/03/2009.

BRASIL. Ministério da Ciência e Tecnologia. Ciência e tecnologia no setor florestal brasileiro: diagnósticos, prioridades e modelo de financiamento. Piracicaba, 2002. Disponível em: <http://www.cgee.org.br/atividades/consultaProduto. php?f=1\&idProduto=1661>. Acesso em: 23/01/2009.

BRUN, F. Biotecnologia aplicada à florestas plantadas e ganhos potenciais de produtividade. In: CONGRESSO INTERNACIONAL DE PRODUTOS DE MADEIRA SÓLIDA DE FLORESTAS PLANTADAS, 2008, 4., Curitiba. Anais... Curitiba: ABIMCI. 1 CD-ROM.

DELGADO, G. C. Expansão e modernização do setor agropecuário no pós-guerra: um estudo da reflexão agrária. Revistas Estudos Avançados, São Paulo, v. 15, n. 43, 2001. Disponível em: <http://www.iea.usp.br/iea/revista/autores/ autoresd.html>. Acesso em: 24/04/2009.

GONÇALVES, J. S. A questão agrária nos clássicos: as idéias, seu tempo e seu lugar. Informações Econômicas, São Paulo, IEA, v. 23, n. 8, 1997.

GUIMARÃES, A. P. G. O Complexo agroindustrial como etapa e via de desenvolvimento das agricultura. Revista de Economia Política, São Paulo, v. 2, n. 3, 1982. Disponível em: <http:// www.rep.org.br/pdf/07-8.pdf>. Acesso em: 24/04/2009.

LINHARES, M. Y.; SILVA, F. C. T. História da agricultura brasileira: combates e controvérsias. São Paulo: Brasiliense, 1981.

MACEDO, A. R. P.; ROQUE, C. A. L. Painéis de madeira. Disponível em: <http://www.bndes.gov.br/conhecimento/Bnset/ painel.pdf>. Acesso em: 15/09/2008.

MARIGHELLA, C. et al. A Questão Agrária no Brasil. 2. ed. São Paulo: Brasil Debates, 1980. 
MARTINI S. T. A competitividade da micro e pequena empresa madeireira na região do Vale do Iguaçu: suas potencialidades e fragilidades. 175 p. Dissertação (Mestrado em Economia) Universidade Federal de Santa Catarina (UFSC), Florianópolis, 2003. Disponível em: <http://www.tede.ufsc.br/teses/ PCNM0091.pdf>. Acesso em: 10/09/2008.

PRADO JR., C. A Revolução Brasileira. 7. ed. São Paulo: Brasiliense, 1987.

RANGEL, I. A História da Dualidade Brasileira. Revista de Economia Política. v. 1, n. 4, out./dez. 1981.

SANDRONI, Paulo. Novíssimo Dicionário de Economia. São Paulo: Best Seller, 1999.
SOCIEDADE BRASILEIRA PARA O PROGRESSO DA CIÊNCIA. Ibama amarra Instituto Chico Mendes. Jornal da Ciência Online, São Paulo, 10 dez. 2007. Disponível em: <http://www.jornaldaciencia.org.br/Detalhe.jsp?id=52961>. Acesso em: 19/05/2010.

VIEIRA, M. G. de D. Formação social brasileira e Geografia: reflexões sobre um debate interrompido. Florianópolis: UFSC, 1992. 
